NASA/CR-2006-213297

\title{
Structural Analysis of Pyrolytic Graphite Optics for the HiPEP Ion Thruster
}

Nicole Meckel and Jonathan Polaha

Aerojet Corporation, Redmond, Washington

Nils Juhlin

NovaComp Engineering, Inc., Bothell, Washington 
Since its founding, NASA has been dedicated to the advancement of aeronautics and space science. The NASA Scientific and Technical Information (STI) Program Office plays a key part in helping NASA maintain this important role.

The NASA STI Program Office is operated by Langley Research Center, the Lead Center for NASA's scientific and technical information. The NASA STI Program Office provides access to the NASA STI Database, the largest collection of aeronautical and space science STI in the world. The Program Office is also NASA's institutional mechanism for disseminating the results of its research and development activities. These results are published by NASA in the NASA STI Report Series, which includes the following report types:

- $\quad$ TECHNICAL PUBLICATION. Reports of completed research or a major significant phase of research that present the results of NASA programs and include extensive data or theoretical analysis. Includes compilations of significant scientific and technical data and information deemed to be of continuing reference value. NASA's counterpart of peerreviewed formal professional papers but has less stringent limitations on manuscript length and extent of graphic presentations.

- TECHNICAL MEMORANDUM. Scientific and technical findings that are preliminary or of specialized interest, e.g., quick release reports, working papers, and bibliographies that contain minimal annotation. Does not contain extensive analysis.

- CONTRACTOR REPORT. Scientific and technical findings by NASA-sponsored contractors and grantees.
- CONFERENCE PUBLICATION. Collected papers from scientific and technical conferences, symposia, seminars, or other meetings sponsored or cosponsored by NASA.

- SPECIAL PUBLICATION. Scientific, technical, or historical information from NASA programs, projects, and missions, often concerned with subjects having substantial public interest.

- TECHNICAL TRANSLATION. Englishlanguage translations of foreign scientific and technical material pertinent to NASA's mission.

Specialized services that complement the STI Program Office's diverse offerings include creating custom thesauri, building customized databases, organizing and publishing research results ... even providing videos.

For more information about the NASA STI Program Office, see the following:

- Access the NASA STI Program Home Page at http://www.sti.nasa.gov

- E-mail your question via the Internet to help@sti.nasa.gov

- Fax your question to the NASA Access Help Desk at 301-621-0134

- Telephone the NASA Access Help Desk at 301-621-0390

- Write to:

NASA Access Help Desk

NASA Center for AeroSpace Information 7121 Standard Drive

Hanover, MD 21076 
NASA/CR-2006-213297

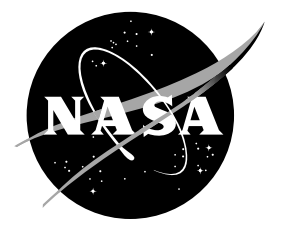

\section{Structural Analysis of Pyrolytic Graphite Optics for the HiPEP Ion Thruster}

Nicole Meckel and Jonathan Polaha

Aerojet Corporation, Redmond, Washington

Nils Juhlin

NovaComp Engineering, Inc., Bothell, Washington

Prepared for the 40th Joint Propulsion Conference and Exhibit sponsored by AIAA, ASME, SAE, and ASEE Fort Lauderdale, Florida, July 11-14, 2004

Prepared under Contract NNC04CB05C

National Aeronautics and Space Administration

Glenn Research Center 


\section{Acknowledgments}

The authors would like to thank John Foster and Tom Haag of NASA Glenn for their help and guidance during this effort. This effort was funded under NASA Contract NNC04CB05C.

Available from

NASA Center for Aerospace Information 7121 Standard Drive

Hanover, MD 21076
National Technical Information Service 5285 Port Royal Road Springfield, VA 22100

Available electronically at http:/ /gltrs.grc.nasa.gov 


\title{
Structural Analysis of Pyrolytic Graphite Optics for the HiPEP Ion Thruster
}

\author{
Nicole Meckel and Jonathan Polaha \\ Aerojet \\ Redmond, Washington 97009 \\ Nils Juhlin \\ NovaComp Engineering, Inc. \\ Bothell, Washington 98041
}

The long lifetime requirements of interplanetary exploration missions is driving the need to develop long-life components for the electric propulsion thrusters that are being considered for these missions. One of the primary life-limiting components of ion thrusters are the optics, which are continuously eroded during the operation of the thruster. Pyrolytic graphite optics are being considered for the High Power Electric Propulsion (HiPEP) ion thruster because of their very high resistance to erosion. This paper describes the structural analysis of the HiPEP pyrolytic graphite optics. A description of the development of the grid model, as well as the development of the effective properties and stress concentrations in the apertured area of the grids is included. An evaluation of the use of curved grids shows that the increased stiffness (compared to flat grids) prevents intergrid impact during launch, however, the residual stresses introduced by curving the grids pushes the resulting peak stresses beyond the critical stress. As a result, flat grids are recommended as the design solution. Thermally induced grid displacements during normal thruster operation are also presented.

\section{Nomenclature}

$D \quad$ Planar distance between grid center and flexure end

$D_{G} \quad$ Grid deflections caused by operational thermal environment

$\Delta \alpha \quad$ Difference in coefficient of thermal expansion between pyrolytic graphite and stainless steel, inches

$\Delta T \quad$ Difference in temperature between room temperature and typical operating temperature

$E_{\text {eff }} \quad$ Effective Young's modulus in the apertured area

$\mathrm{Ka}$ Stress concentration Factor in apertured area

$\sigma^{\max } \quad$ Peak stress

$\rho_{\text {eff }} \quad$ Effective material density in the apertured area

$\rho_{P G} \quad$ Material density of pyrolytic graphite

$R_{A} \quad$ Open area fraction in the apertured area

\section{Introduction}

ION propulsion systems are very attractive and, in some cases, enabling for outer planetary exploration missions. Previous studies ${ }^{1}$ have shown that the use of high power, high $\mathrm{I}_{\mathrm{sp}}$ ion propulsion is attractive both in terms of payload mass and trip times. Despite the minimized trip time, the operational life requirements for these missions is very high. For missions such as the proposed Jupiter Icy Moons Orbiter (JIMO) and similar missions, operational lifetimes of $80 \mathrm{k}$ hours or more would be necessary. Increasing the lifetime of ion propulsion systems has therefor become an important area for the improvement of this technology.

The ion optics are one of the primary lifetime limiting subassemblies in the ion thruster. The accelerator grid is eroded over time by charge-exchange ions that are produced immediately downstream of the optics. ${ }^{2}$ The Molybdenum grids used on the NSTAR mission were shown to survive for $30.0 \mathrm{k}^{\text {hours }}{ }^{3}$ although at an average power less than full power. Many investigations have been conducted to evaluate the use of materials with lower sputter yields than Molybdenum. Prominent among these materials are carbon-carbon and pyrolytic graphite. Carbon-carbon and pyrolytic graphite both offer almost an order of magnitude reduction in sputter yield, ${ }^{4-6}$ and a 
near-zero coefficient of thermal expansion (CTE), a feature that enables the use of flat grids at close grid spacing. This combination of features makes both materials highly attractive for these long duration missions. Carbon-carbon composites offer reasonable densities $\left(.054-.068 \mathrm{lb} / \mathrm{in}^{3}\right)$, which effectively provides more material to sputter away, as well as extremely high stiffness. Though to fully reap this latter benefit, continuous fibers must be maintained across the grid surface area. The approach used in several recent efforts that investigated carbon-carbon composites was to drill the ion apertures in a carbon-carbon laminate; resulting in cutting virtually all of the continuous fibers in the original laminate. ${ }^{7}$ Others have sought novel approaches to utilizing continuous fibers, though this was a laborintensive approach and it is somewhat limited to thicker grids and smaller open area fractions. ${ }^{8}$ The continuous unidirectional fibers can also create significant anisotropy in the properties of the material. This effect can be seen in table one, below. The combination of these issues has provided the motivation for investigating pyrolytic graphite. NASA GRC ${ }^{9}$ has shown success in the fabrication and test of circular ion optics using Pyrolytic graphite. This recent success has lead the HiPEP program to consider the use of pyrolytic graphite.

Pyrolytic graphite offers the same benefits in terms of sputter yield, density, and low CTE as carbon-carbon, but does not have these integral fibers. As shown in table one, below, pyrolytic graphite does not provide the strength or stiffness of virgin carbon-carbon, however, the material properties of pyrolytic graphite are not as significantly compromised by the machining of the apertures as is the case for carbon-carbon.

TABLE 1.-COMPARISON OF THE PROPERTIES OF PYROLYTIC GRAPHITE AND CARBON-CARBON MATERIALS ${ }^{6,10}$

\begin{tabular}{|c|c|c|c|}
\hline Material & Flexural Strength, ksi & $\begin{array}{c}\text { Young’s Modulus, } \\
\text { Msi }\end{array}$ & Density lb/in $^{3}$ \\
\hline Pyrolytic Graphite $^{\mathrm{a}}$ & $11.6-24.7$ & $4.06-4.50$ & $0.076-0.081$ \\
\hline $\begin{array}{c}\text { Carbon-Carbon with } \\
0^{\circ}+60^{\circ} / 60^{\circ} \text { Fibers }\end{array}$ & $29.7^{\mathrm{b}} / 17.0^{\mathrm{c}}$ & 21.03 & 0.066 \\
\hline $\begin{array}{c}\text { Carbon-Carbon with } \\
0^{\circ} / 0^{\circ} / 90^{\circ} \text { Fibers }\end{array}$ & $41.9^{\mathrm{b}} / 7.3^{\mathrm{c}}$ & $33.36^{\mathrm{b}} / 17.55^{\mathrm{c}}$ & 0.068 \\
\hline
\end{tabular}

The work recently completed at NASA GRC demonstrated that flat pyrolytic graphite grids could survive typical launch environments ${ }^{11}$. Despite this success, structural issues remain the greatest concern in the implementation of pyrolytic graphite grids for the HiPEP ion thruster. The objective of the analyses described in this paper were to determine whether pyrolytic graphite grids could survive the dynamic environment anticipated for a JIMO-type mission with margin; identify possible issues; and evaluate means to mitigate these issues. This paper provides a background to the development of the grid model; an evaluation of the effect of curving the grids; and the grid response to thermally induced displacements during the operation of the thruster.

\section{Stress Analysis}

\section{A. Structural Model Development}

The flat, rectangular grids have two specific regions. The center, a 36-inch by 16-inch aperture region, has open area fractions of 0.66 and 0.24 for the screen grid and acceleration grids, respectively. The outer perimeter of the center region is solid pyrolytic graphite that serves as an extension to accommodate the space required by the relatively large insulators. The edges of the grids are reinforced with square cross-section pyrolytic graphite stiffeners that which also serve as the mounting interface to the grid flexures. Each grid is mounted on twenty-two evenly spaced metallic blade-type flexures that provide the interface between the optics and the thruster structure. The axis of each of these flexures is perpendicular to the plane of the grids. The pyrolytic graphite grids have a nearzero coefficient of thermal expansion (CTE), thus; the flexures are designed to bend to accommodate the CTE mismatch between the grids and the thruster structure. To facilitate this bending, each of the blade flexures is oriented such that the vector normal to the flat face of the blade points towards the grid center. For the analyses in this paper, the flexures are modeled as beam elements with appropriately oriented moments of inertia. Both ends of the flexure are fixed for these calculations.

\footnotetext{
${ }^{\text {a }}$ Material properties vary with degree of graphitization

${ }^{\mathrm{b}} 0^{\mathrm{o}}$ Direction

${ }^{\mathrm{c}} 90^{\circ}$ Direction
} 
From a structural point of view, the apertures introduce stress concentrations that must be accounted for in the structural model. To include every aperture in the structural models would be a daunting task. Instead, an approach was developed where a rectangular plate without any apertures can be used for the structural analysis. In the center region where the apertures are supposed to be, effective properties are used to represent the stiffness and density of the aperture region. Keeping the thickness constant over the entire plate, the effective density in the aperture region was defined by

$$
\rho_{\text {eff }}=\left(1-R_{A}\right) \rho_{P G}
$$

where $R_{A}$ is the open area fraction and $\rho_{P G}$ is the density of pyrolytic graphite. Two subscale models were developed. One model including the apertures and one model without apertures as shown in figure 1.

To evaluate the effect of the apertures on stiffness, boundary conditions and symmetry conditions were applied such that the two models shown in figure 1 represent quarter models of a clamped plate. Eigenvalue analyses were conducted on both models. The modulus, $E_{\text {eff, }}$ for the effective property subscale model was modified in an iterative manner until the eigenvalues agreed with the eigenvalues of the actual subscale model. Once having determined $\rho_{\text {eff }}$ and $E_{\text {eff }}$, the next step was to develop a method for extracting actual stresses from the effective property models. By applying a transverse gravitational load to the models in figure 1, a direct comparison of the stresses, as shown in figure 2 , leads to the definition of the aperture stress concentration as

$$
K_{a}=\frac{\sigma_{\text {aperture }}^{\max }}{\sigma_{\text {effective }}^{\max }}
$$

Using this approach, the stress concentration factors shown in table 2 were obtained for aperture regions in the screen and acceleration grids. The stresses calculated in the apertured regions are multiplied by this stress concentration factor to achieve the actual peak stresses.

\section{TABLE 2.-STRESS CONCENTRATION FACTORS} DERIVED FROM SUBSCALE STRUCTURAL MODELS

\begin{tabular}{|l|c|}
\hline & Stress concentration factor, $K_{a}$ \\
\hline Screen Grid & 5.9 \\
\hline Acceleration Grid & 2.6 \\
\hline
\end{tabular}

A single finite element model was developed for analyzing both the acceleration and the screen grids. The model consists of the grid and supporting flexures as shown in figure 3. The grid stiffeners are represented by plate elements along the outer perimeter of the non-aperture region. The flexures are coupled to the grid stiffeners in all six degrees of freedom with the free ends constrained in all six degrees of freedom.

The actual properties of the pyrolitic graphite are slightly anisotropic. The absence of accurate multidirectional material test data limits the analysis to use of isotropic constitutive material models. The material properties used in the analyses are shown in table 3.

TABLE 3.-MATERIAL PROPERTIES USED IN GRID ANALYSIS ${ }^{12}$

\begin{tabular}{|l|c|c|c|c|}
\hline \multicolumn{1}{|c|}{ Property } & $\begin{array}{c}\text { Pyrolytic } \\
\text { graphite }\end{array}$ & $\begin{array}{c}\text { Pyrolitic graphite; } \\
\text { acceleration grid } \\
\text { effective property }\end{array}$ & $\begin{array}{c}\text { Pyrolitic graphite; } \\
\text { screen grid effective } \\
\text { property }\end{array}$ & $\begin{array}{c}\text { Flexures } \\
\text { (stainless steel) }\end{array}$ \\
\hline Specific weight $\left({\left.\mathrm{lb} / \mathrm{in}^{3}\right)}^{3}\right.$ & 0.080 & 0.062 & 0.028 & 0.283 \\
\hline Elastic modulus $(\mathrm{msi})$ & 4.00 & 2.56 & 0.848 & 29.00 \\
\hline Poisson's ratio & 0 & 0 & 0 & 0.27 \\
\hline
\end{tabular}

For assessing the analysis results, the tensile strength of $13 \mathrm{ksi}$ is used for the pyrolitic graphite. A factor of safety of 2.0 is applied to all stresses calculated for the pyrolitic graphite in both the aperture and non-aperture regions. 


\section{B. Application of Vibration Spectra}

The most critical load for the optics assembly is the launch environment. Because the proposed JIMO mission is a primary target for the HiPEP thruster, the anticipated JIMO launch dynamic environment was used for the random vibration analyses.

Modal analysis of the grids indicates the worst case load direction for evaluating the grid response to be normal to the grid planes. Applying the PSD transverse to the grids yields the greatest deflections and stresses. Therefore, the analysis was focused on transverse loading.

The initial analyses were conducted assuming flat grids. These results, which are included later in this paper, showed that, while the predicted peak stresses are within the acceptable range, the predicted displacement of each grid was sufficient to assure impact between the grids during launch. The effect of intergrid impact is not well understood. The results of the NASA GRC work ${ }^{11}$ showed no damage from impact during vibration testing. Despite this result, the risk of damage due to intergrid impact raises concerns. An evaluation was thus conducted to determine if this impact could be minimized or eliminated by stiffening the grids by bending them into a curved configuration. Mechanically bending the grids will result in residual stresses that will be present in the optics assembly. These residual stresses are added to stresses induced by the dynamic environment to determine the resulting peak stresses. In this section, the effects of grid bending on the structural response are illustrated with comparison to flat grid responses.

There are two potential effects on the modal response of the grids from bending the flat grids into curved grids. One is the geometric change and the second is the stiffening effect from the resulting residual stresses. To account for both of these nonlinear effects the finite element code ABAQUS ${ }^{13}$ was used. In order to develop a finite element model for evaluating the modal response of the grids that incorporates the simulation of grid bending without generating additional membrane stresses, the following steps were taken:

step 1. Release coupling between flexures and grid

step 2. Apply rotations along both long edges until achieving the desired curvature height to span ratio. Allow long edges to displace inward such that only bending stresses are developed.

step 3. Generate stress free grid stiffeners along all four grid edges

step 4. Relocate flexures and couple them to grid stiffeners, add constraints to flexure ends and release the grid constraints used to bend the grids.

step 5. Conduct modal analysis.

In order to determine the effect of the residual stresses, additional analyses were conducted where the grids were stress relieved just before step 4. Comparing modal frequencies indicated that the stiffening effect from the residual bending stresses is negligible. As a result, the modal and random vibration analysis can be done with stress free, pre-curved grids, eliminating the need for nonlinear analysis. Even though the stiffening effect is negligible, the residual stresses associated with bending the grids are significant. The peak residual stresses for various curvature heights to span ratios are given in figure 4 .

The curved shapes for the three different curvature height to span ratios were extracted from ABAQUS results and used to generate the nodal locations for the NISA models used for modal and random vibration analysis. In order to compare the grid modes, the flexure stiffness was artificially increased to eliminate flexure modes. A comparison of the first few grid mode frequencies is included in table 4. These results clearly illustrate the strong dependency of the modal response to the geometric shape of the grids.

TABLE 4.-COMPARISON OF PRIMARY MODAL FREQUENCIES FOR VARIOUS CURVATURE HEIGHT TO SPAN RATIOS

\begin{tabular}{|c|c|c|c|c|c|c|}
\hline \multirow{2}{*}{$\begin{array}{l}\text { Curvature height } \\
\text { to span ratio }\end{array}$} & \multicolumn{2}{|c|}{ Acceleration grid frequencies (Hz) } & \multicolumn{3}{c|}{ Screen grid frequencies (Hz) } \\
\cline { 2 - 7 } & Mode 1 & Mode 2 & Mode 3 & Mode 1 & Mode 2 & Mode 3 \\
\hline 0.0 (flat grid) & 26 & 34 & 49 & 22 & 27 & 37 \\
\hline 0.0156 & 65 & 70 & 86 & 58 & 71 & 74 \\
\hline 0.0313 & 77 & 104 & 110 & 70 & 85 & 101 \\
\hline 0.0469 & 88 & 116 & 139 & 84 & 89 & 117 \\
\hline
\end{tabular}

When analyzing for the response to the anticipated JIMO dynamic environment, the properties for the round rod flexures were used. This is more realistic than assuming rigid flexures and slightly reduces the grid mode frequencies. The resulting flexure modes are bending modes and do not provide any vibration isolation for the grid deflection modes. The random vibration analysis yields the displacements shown in figure 5 and stress results given 
in figure 6 for the acceleration grid and in figure 7 for the screen grid, where the total stress is the sum of the threesigma stress and the residual stress. As can be seen in these figures, only grids with a curvature height to span ratio of less than 0.01 have peak stresses less than the critical stress of $6.5 \mathrm{ksi}$ (for the factor of safety of 2.0). These results indicate that flat grids provide a better design solution than mechanically curved grids.

\section{C. 'Snap Through' Analysis}

The static transverse loads of the launch environment can cause 'snap through' in the curved grids. To determine what loading would cause this behavior for each level of grid curvature, ABAQUS was used to run collapse analysis on the grids using Riks method for large displacement responses. Figure 8 shows the g-levels required to buckle the grids as a function of the curvature height to span ratios. The overall RMS acceleration of the JIMO launch environment is $10 \mathrm{~g}_{\mathrm{rms}}$. Applying the commonly employed three-sigma design criteria indicates that the grids will be exposed to gravitational loads of up to $30 \mathrm{~g}$. Therefore, the curvature height to span ratio should be 0.032 or greater.

The above results indicate that bending flat grids to form curved grids will yield thruster optics results in reduced structural capability when compared to flat grids. At higher curvature height-to-span ratios, the residual stresses are excessively high, and at lower curvature height-to-span ratios, the grids are prone to "snap through" buckling behavior. The remaining optics design solutions are thus either flat grids, or manufactured curved grids (which are discussed below).

\section{Manufactured Curved Grids}

A method for achieving the increased stiffness of curved grids without creating the residual stresses of mechanically bending the grids is to manufacture the grids in a curved configuration. Manufactured curved grids with a height to span ratio of at least 0.032 would have sufficient stiffness to eliminate impact between the grids during launch and to avoid buckling due to the static loads. In addition, because of the lack of residual stresses in the manufactured curved grids, the peak loads in these grids would be well below those predicted for either flat grids or mechanically bent grids. Manufacturing curved grids of this size, and of the required quality requires process development.

\section{Thermal Effects}

Grid deflections during launch are not critical to the performance of the optics assembly as they return to their flat configuration post launch. Of greater concern to thruster performance, specifically for flat grids, are the deflections that occur due to the operational thermal environment in space. The low CTE of the pyrolytic graphite requires the use of the flexures to accommodate the thermal expansion of the supporting thruster structure. As the thruster structure expands with respect to the optics, bending moments are induced in the grids through the cantilevered flexures. These bending moments cause deflections in the grids that could change the grid gap, and thus effect thruster performance. The effect of this CTE mismatch can be analyzed using the finite element model shown in figure 3. The flexure properties in the model were set to allow for flexure bending to accommodate for some of the CTE mismatch while maintaining grid alignment and grid gap as much as possible. The magnitude of the grid deflections, $\mathrm{D}_{\mathrm{G}}$, are calculated as:

$$
D_{G}=\Delta \alpha \Delta T D
$$

where $\Delta \alpha$ is the difference in CTE between the pyrolytic graphite and steel at $480{ }^{\circ} \mathrm{C}\left(\sim 8.5 \times 10^{-} 6\right.$ in/in $\left.{ }^{\circ} \mathrm{F}\right)$, $\Delta \mathrm{T}=414^{\circ} \mathrm{F}$, and $\mathrm{D}$ is the planar distance from the grid center to the flexure end. The resulting deformed shape is shown on the quarter model in figure 9 . The center deflections are $22 \%$ and $24 \%$ of the grid gap for the acceleration and screen grids, respectively. Both deflections are in the same direction, resulting in a total change in grid gap of $2 \%$. This change in grid gap is small in terms of it's impact on the performance of the optics. The associated grid stresses are less than 1000 psi. These results are of course flexure specific. The amount of grid deflection will decrease with less stiff flexures. The importance of this study is to illustrate that the flexures must be optimized to accommodate the thermal expansion and still support the grids during launch.

\section{Conclusions}

Analysis has shown that flat grids should survive the launch loads for the proposed JIMO mission, and, because of their configuration, are impervious to the risk of 'snap through' buckling. Based on the predicted displacements, the grids would impact each other during launch. Though previous efforts have shown minimal damage due to 
intergrid impact, vibration testing of the optics will be necessary to verify the robustness of the flat pyrolytic optics for the flight application.

The increased stiffness from the curved geometry prevents grid contact during launch and significantly reduces grid stresses. Bending flat grids to have curved geometry provides the required increase in stiffness. However, significant curvatures are required to avoid buckling from launch loads and the resulting residual stresses become exceedingly high. These residual bending stresses can be eliminated by utilizing manufactured curved grids.

Manufactured curved grids could provide an optimal grid design for the HiPEP optics assembly. Should the results of future testing show that the flat optics design is susceptible to damage during launch, the HiPEP program would develop the manufacturing processes necessary to produce manufactured curved grids.

Thermal expansion of the optic's supporting structure must be considered when designing the flexures and the flexure fastener components. The stiffness of the flexures should be minimized to accommodate thermal expansion without compromising the structural integrity during launch loads.

The work presented in this paper focused mainly on the mechanical response of the grids to vibration and thermal environments. The design of the flexures and flexure joints is also crucial to the overall performance of the optics assembly. Future analysis efforts will be directed towards the optimization of these components and the resulting effects on the grids.

\section{Aerojet Efforts on HiPEP and Future Work}

Aerojet is supporting the NASA-GRC HiPEP effort with the design, analysis and fabrication of the Development Model (DM) thruster. This thruster will undergo vibration and performance testing prior to the completion of this phase of the HiPEP development program.

\section{References}

${ }^{1}$ Oleson, S. and Katz, I., "Electric Propulsion for Project Prometheus", AIAA-2003-5279, Presented at the $39^{\text {th }}$ Joint Propulsion Conference, July 2003.

${ }^{2}$ Monheiser, J.M. " Development and Verification of a Model to Predict Impingement Currents for Ion Thrusters", NASA CR-195322, April 1994.

${ }^{3}$ Sengupta, A., Brophy, J., Anderson, J., and Garner, C., "An Overview of the Results from the 30,000 Hour Life Test of the Deep Space 1 Flight Spare Ion Engine", AIAA-2004-3604, to be presented at the $39^{\text {th }}$ Joint Propulsion Conference, July 2004.

${ }^{4}$ Meserole, J.S. "Measurement of Relative Erosion Rates of Carbon-Carbon and Molybdenum Ion Optics", AIAA-94-3119, Presented at the $30^{\text {th }}$ Joint Propulsion Conference, June 1994.

${ }^{5}$ Snyder, J.S., "Review of Carbon-Based Grid Development Activities for Ion Thrusters", AIAA-2003-4715, Presented at the $39^{\text {th }}$ Joint Propulsion Conference, July 2003.

${ }^{6}$ Pearson, H.O., "Handbook of Carbon, Graphite, Diamond and Fullerenes: Properties, Processing, and Applications", Noyes Publications, Park Ridge, N.J., c1993.

${ }^{7}$ Haag, T., Patterson, M, Rawlin, V. and Soulas, G., "Carbon-based Optics Development at NASA GRC", IEPC-01-94, Presented at the $27^{\text {th }}$ International Electric Propulsion Conference, October 2001.

${ }^{8}$ Kitamura, S. Hayakawa, Y., Kasai, Y. and Ozaki, T., "Fabrication of Carbon-Carbon Composite Ion Thruster Grids Improvement of Structural Strength", IEPC -97-093, Proceedings of the $25^{\text {th }}$ International Electric Propulsion Conference, Volume I, pp. 586-593.

${ }^{9}$ Haag, T. and Soulas, G. C., "Performance of $8 \mathrm{~cm}$ Pyrolytic-Graphite Ion Thruster Optics", AIAA-2002-4335, Presented at the $37^{\text {th }}$ Joint Propulsion Conference, July 2002.

${ }^{10}$ Mueller, J., Brophy, J.R., and Brown, D.K., "Endurance Testing and Fabrication of Advanced 15-cm and $30 \mathrm{~cm}$ CarbonCarbon Composite Grids", Aiaa-95-2660, Presented at the $31^{\text {st }}$ Joint Propulsion Conference, July 1995.

${ }^{11}$ Haag, T. and Soulas, G. C., "Performance and Vibration of $30 \mathrm{~cm}$ Pyrolytic Ion Thruster Optics", AIAA-2003-4557, Presented at the $38^{\text {th }}$ Joint Propulsion Conference, July 2003.

12 "Pyrolytic Graphite", Mineral Technologies, Inc. Webpage, http://www.mineralstech.com/graphite.html.

${ }^{13}$ ABAQUS Finite Element Modeling Code, Version 6.3, Hibbit, Karlsson, \& Sorensen, Inc., Pawtucket, RI. 


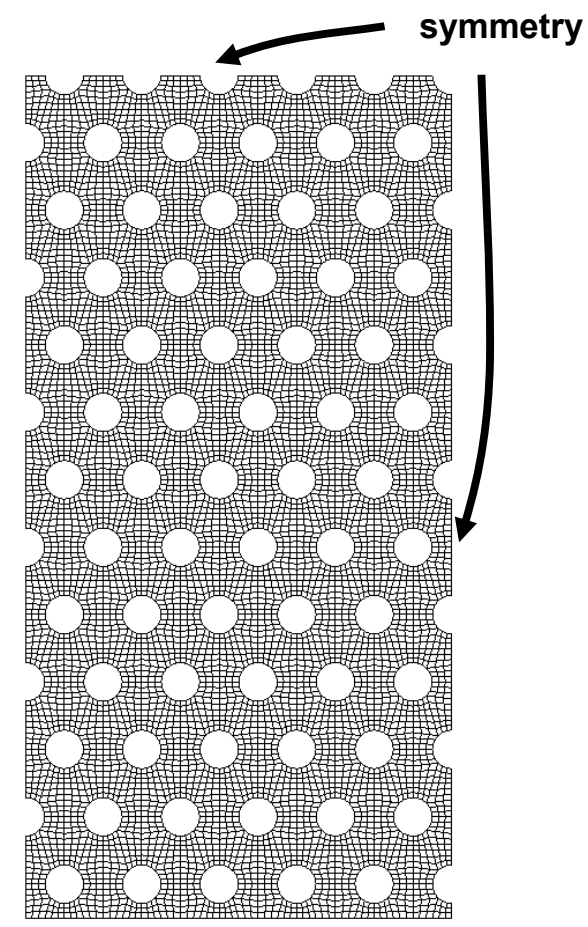

(a)

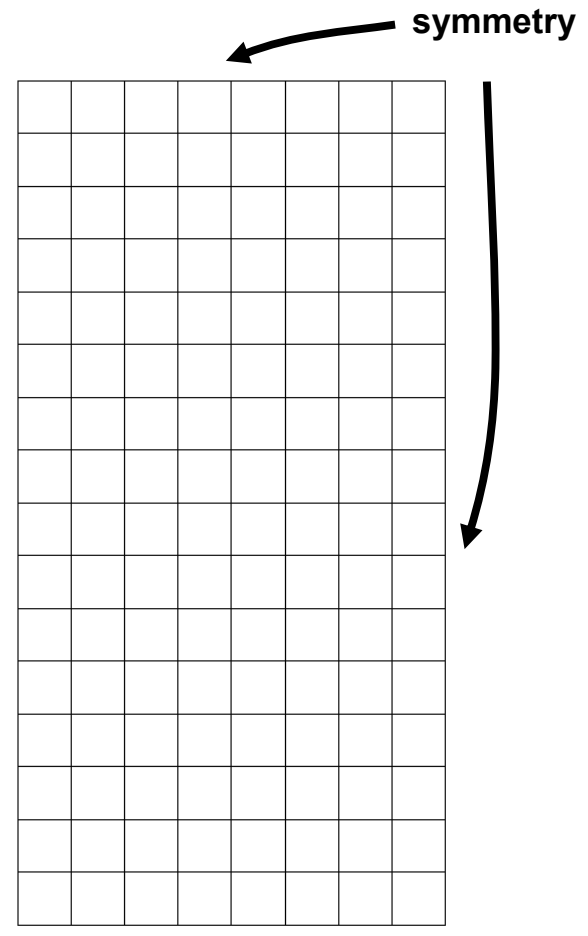

(b)

Figure 1.- a) Actual subscale structural model and b) effective propertv subscale structural model
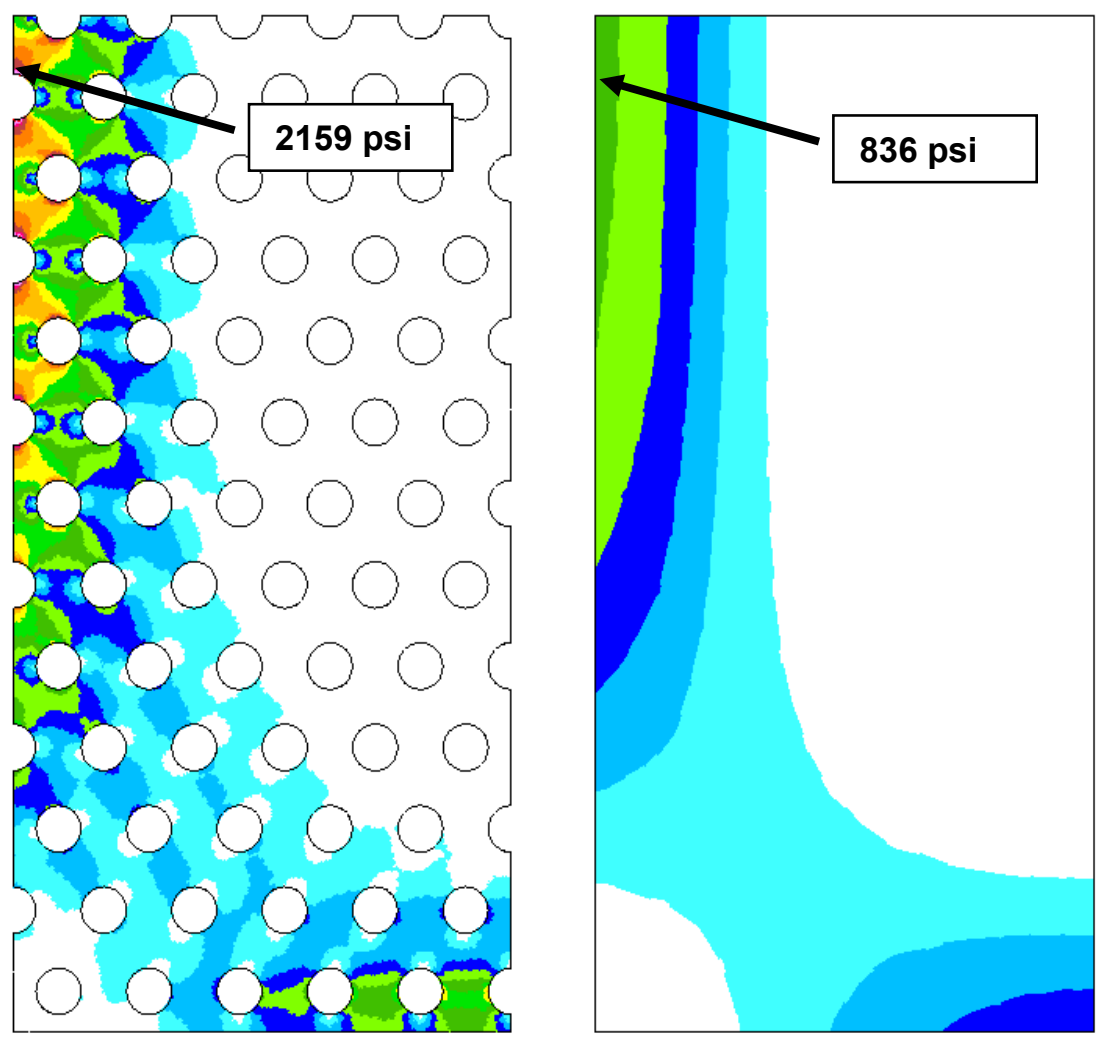

VIEW : 0 .

RANGE: 2159.297

(Band * 1.0E1)

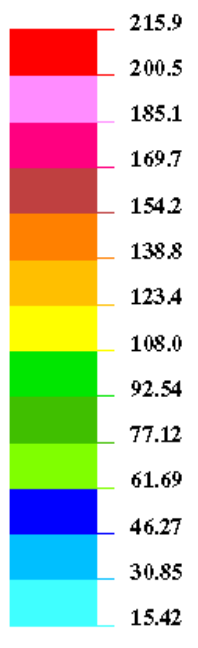

0.0

EMRC-NISADISPLAY

FEB/23/04 14:58:15

$\begin{array}{ll}\text { Y } & \begin{array}{l}\text { ROTX } \\ 0.0 \\ \text { ROTY } \\ n n\end{array}\end{array}$

Figure 2.-Comparison of actual stresses and effective stresses for the determination of stress concentration factors (acceleration grid is shown). 


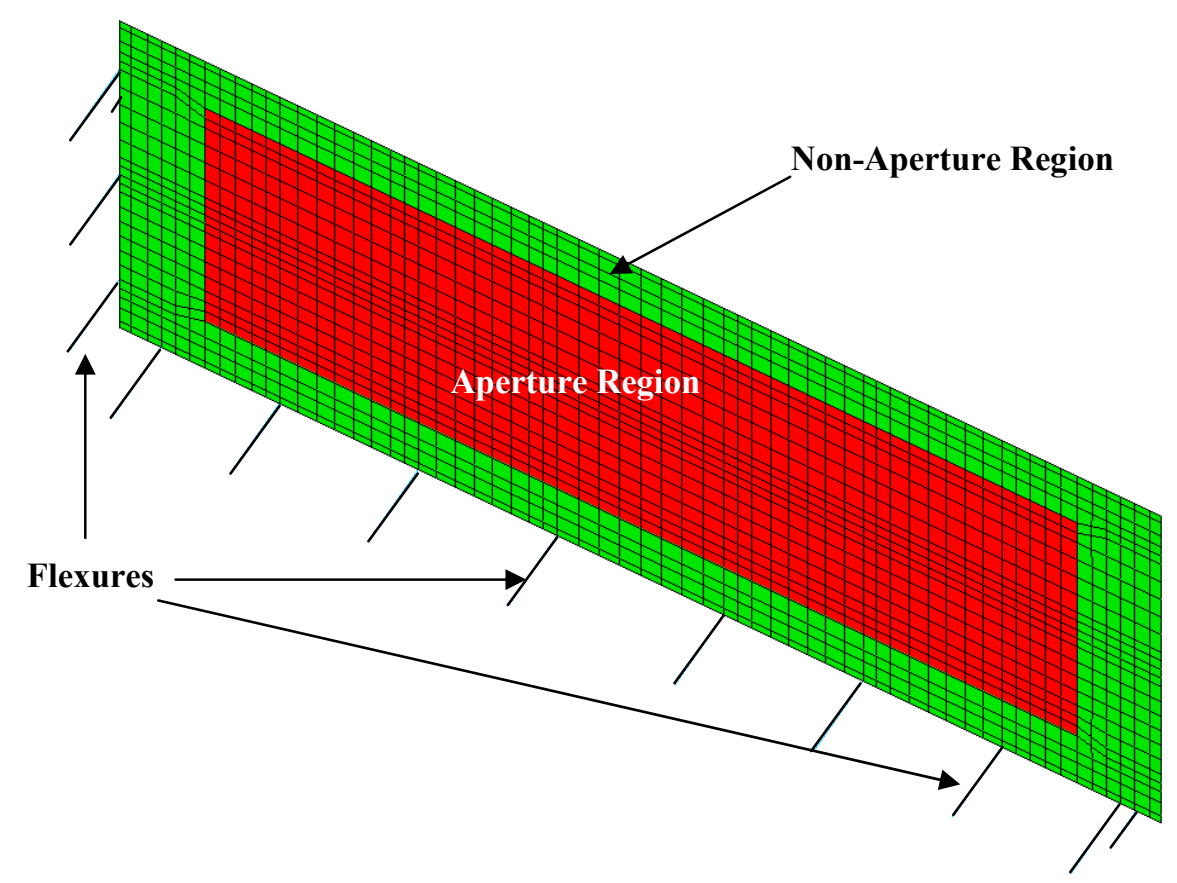

Figure 3.-Grid finite element model

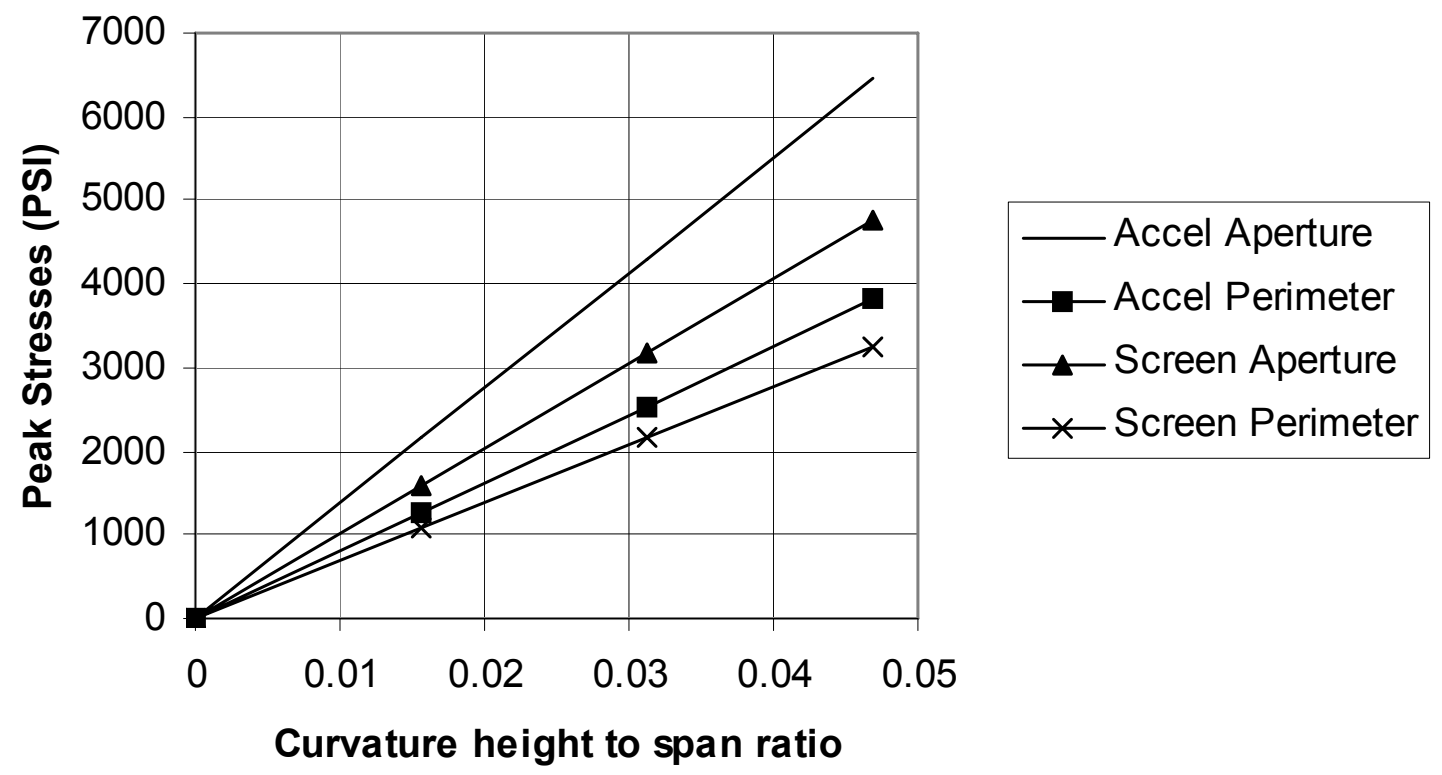

Figure 4.-Peak Residual Stresses as a function of Curvature 


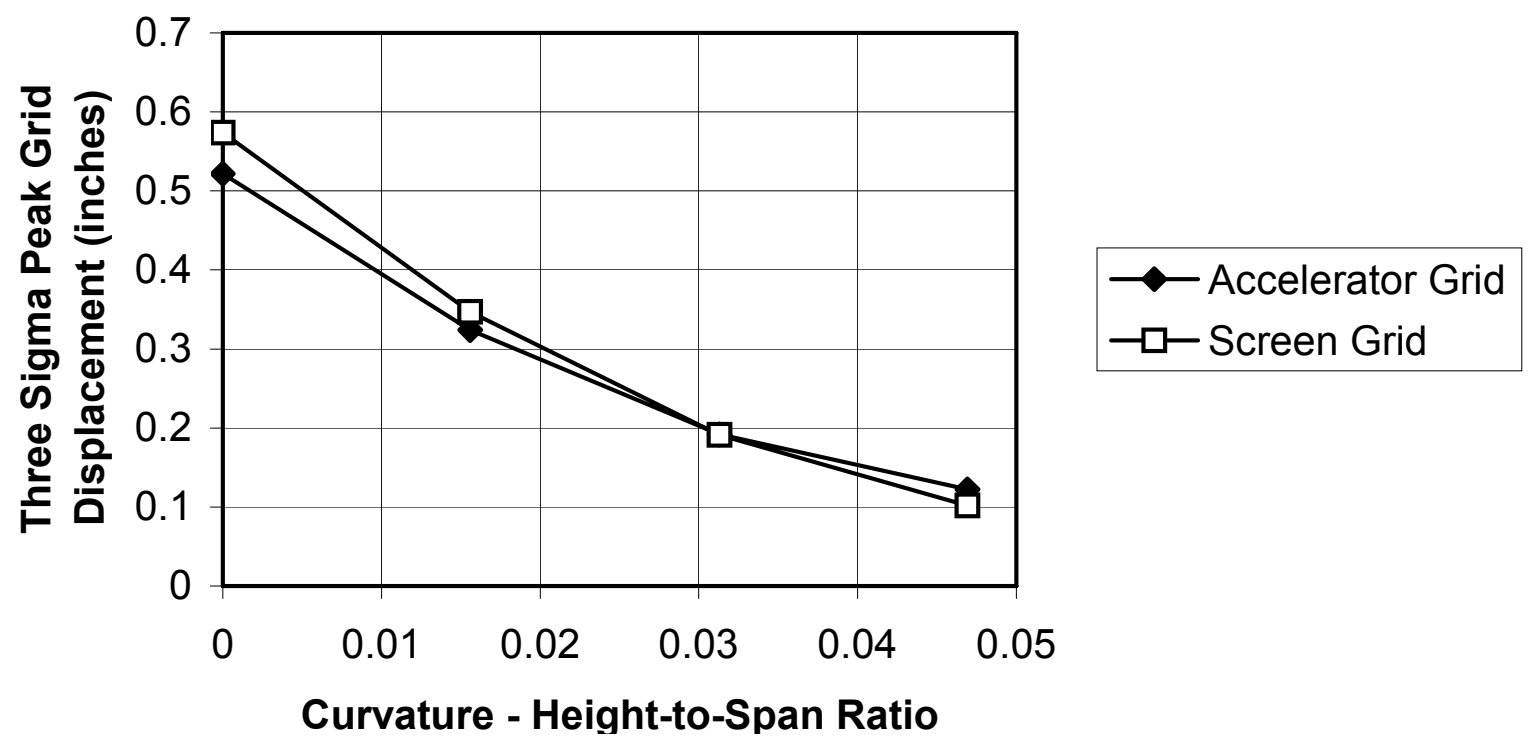

Figure 5.-Peak Displacement as a Function of Grid Curvature - from the Random Vibration Analysis

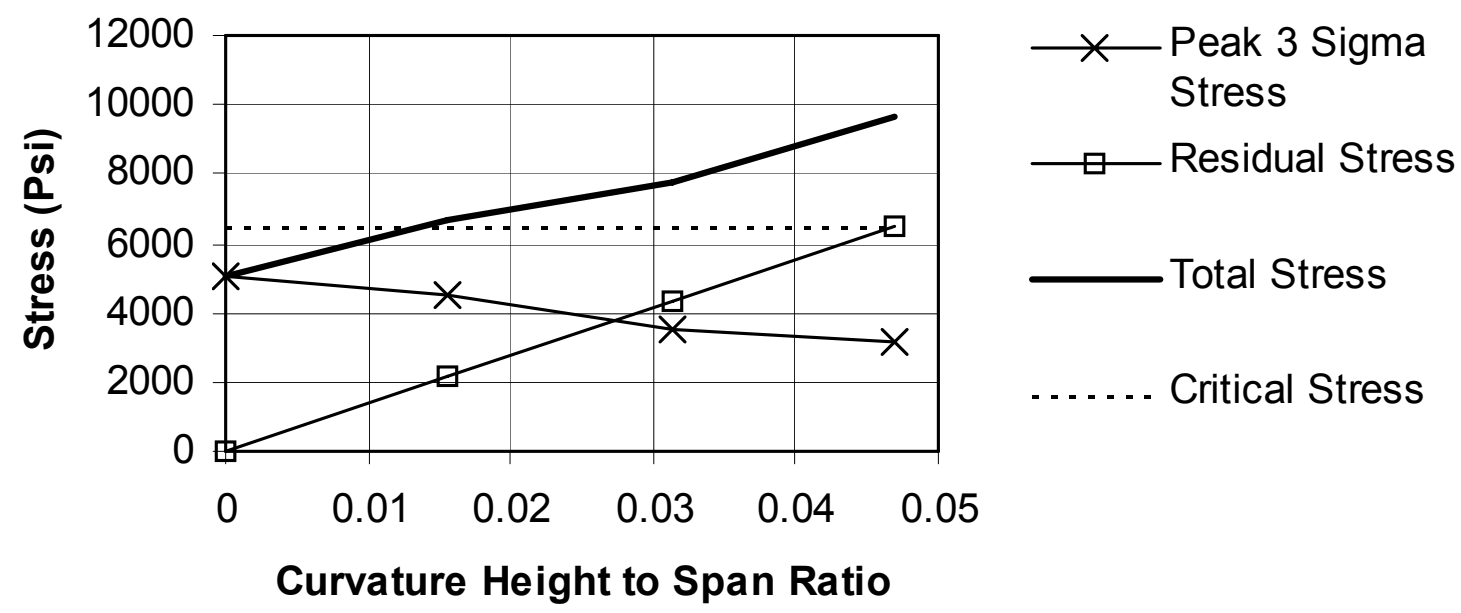

Figure 6.-Peak Stress as a function of Grid Curvature for the Accelerator Grid 


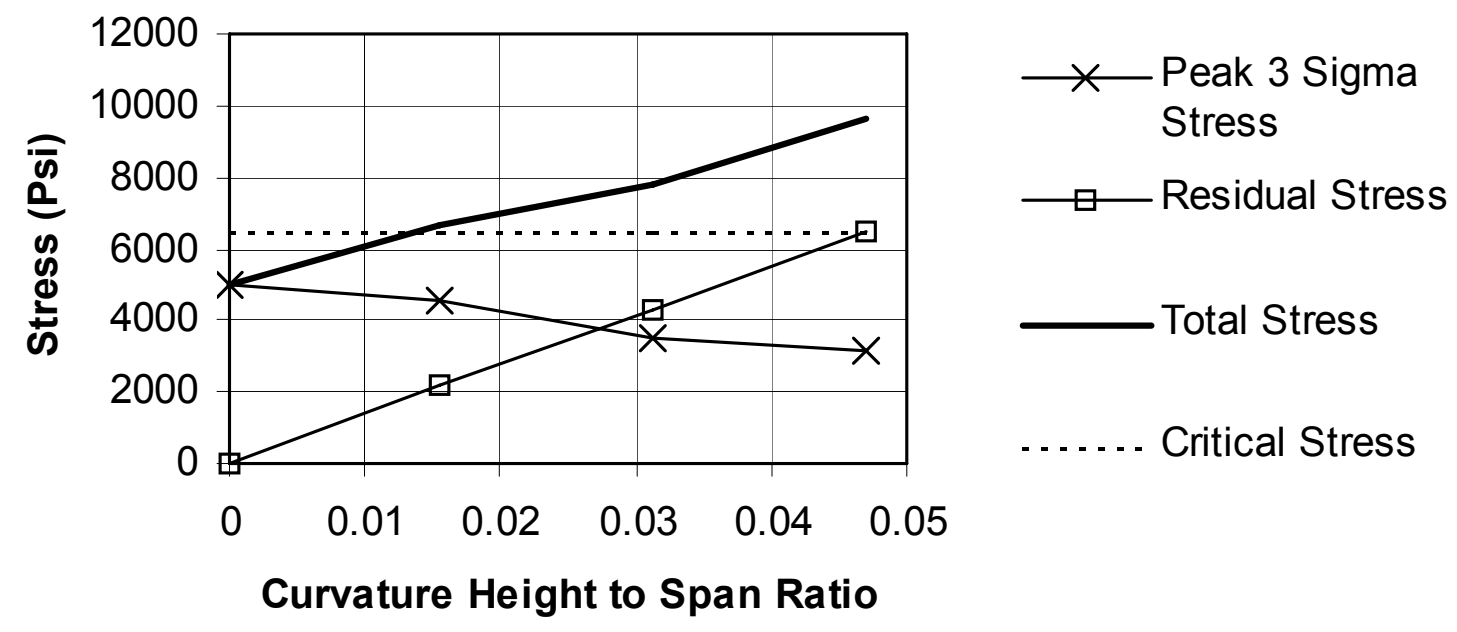

Figure 7.-Peak Stress as a function of Grid Curvature for the Screen Grid

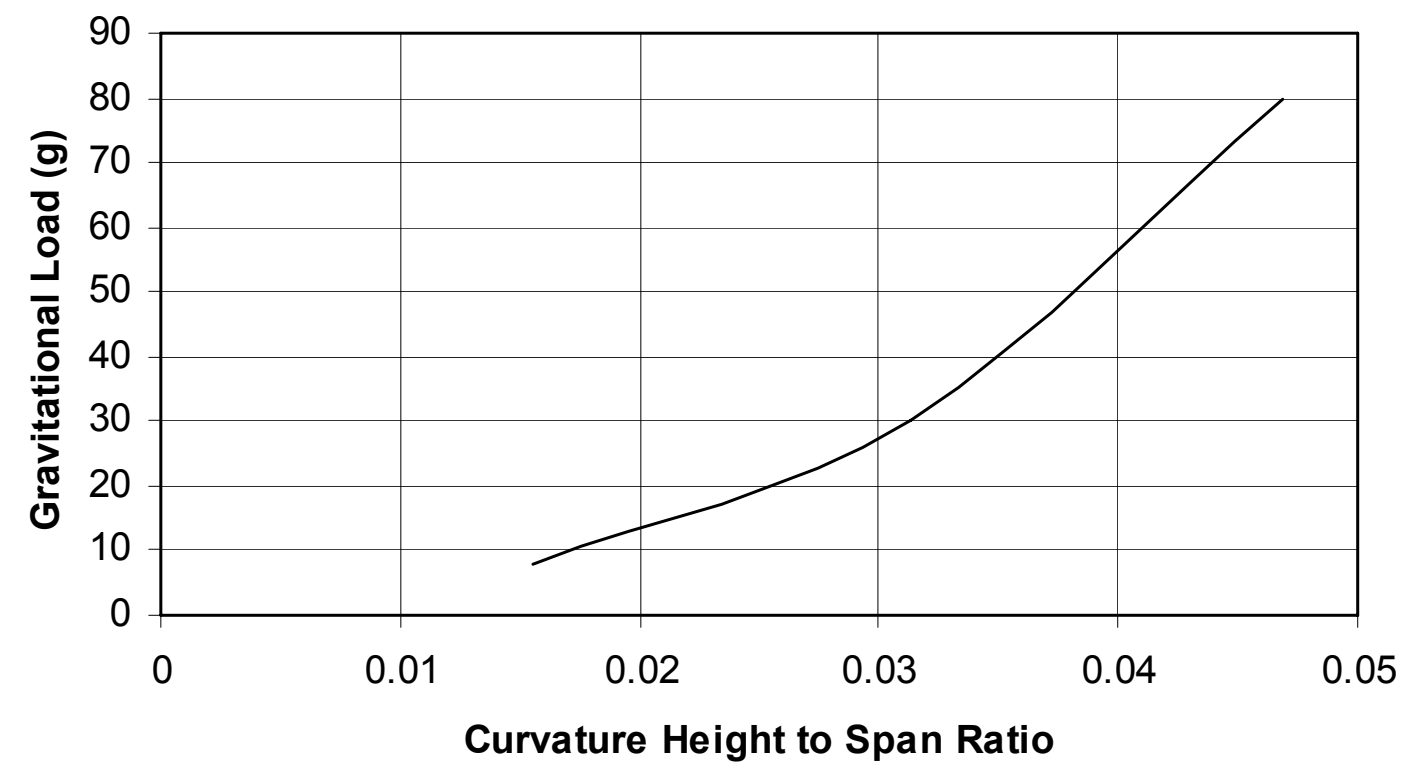

Figure 8.-Gravitational loads required to buckle curved grids. 


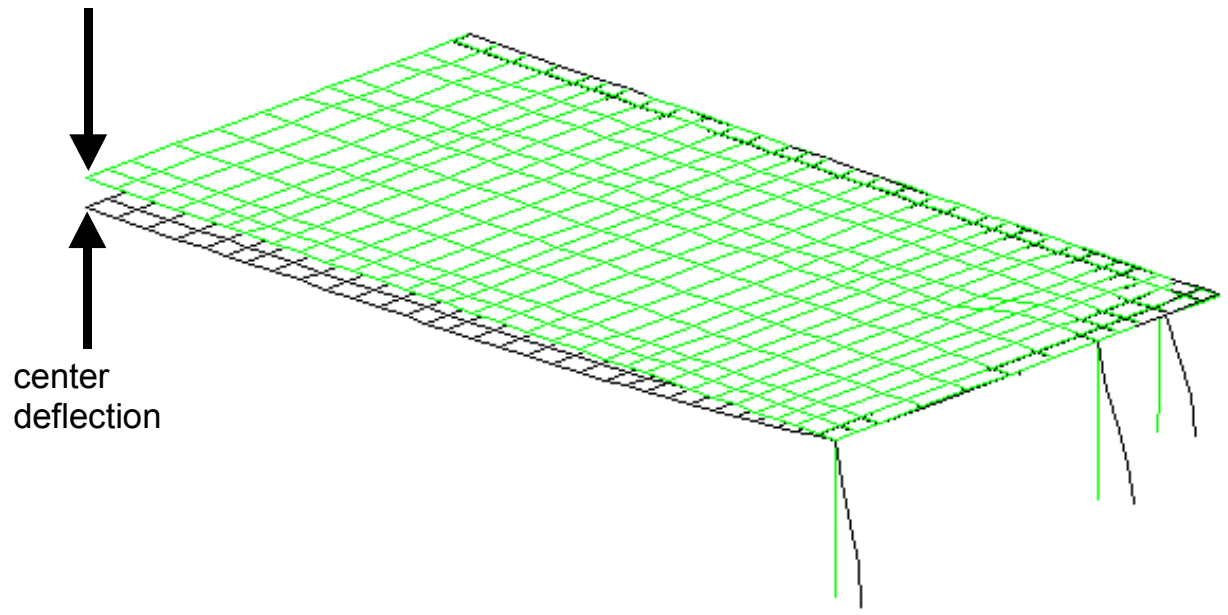

Figure 9.-Deformed grid/flexure assembly due to thermal expansion of the thruster structure 


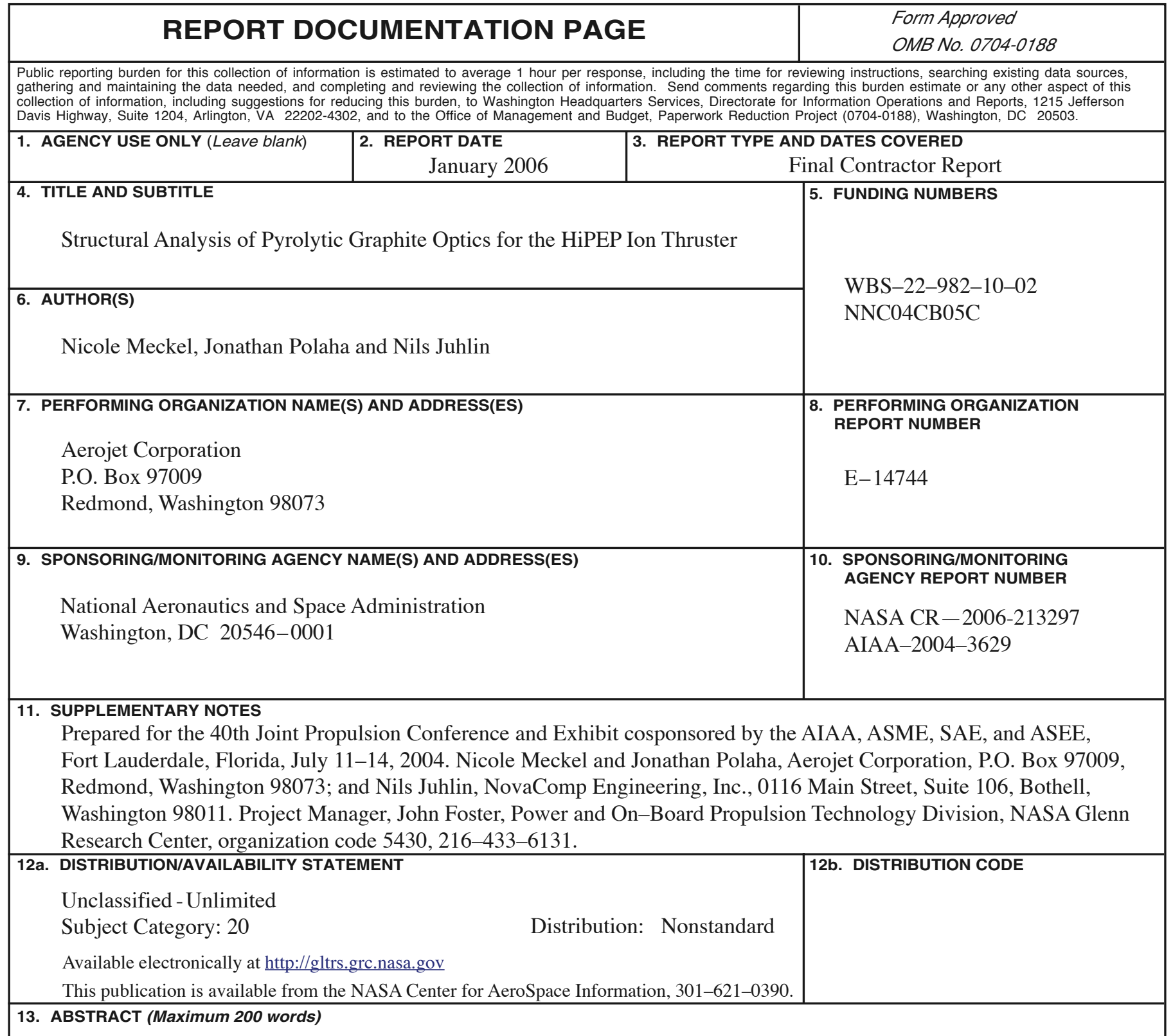

The long lifetime requirements of interplanetary exploration missions is driving the need to develop long-life components for the electric propulsion thrusters that are being targeted for these missions. One of the primary life-limiting components of ion thrusters are the optics, which are continuously eroded during the operation of the thruster. Pyrolytic graphite optics are being considered for the High Power Electric Propulsion (HiPEP) ion thruster because of their very high resistance to erosion. This paper describes the structural analysis of the HiPEP pyrolytic graphite. A description of the development of the grid model, as well as the development of the effective properties and stress concentrations in the apertured area of the grids is included. An evaluation of the use of curved grids shows that the increased stiffness (compared to flat grids) prevents intergrid impact during launch, however, the residual stresses introduced by curving the grids pushes the resulting peak stresses beyond the critical stress. As a result, flat grids are recommended as the design solution. Thermally induced grid displacements during normal thruster operation are also presented.

\begin{tabular}{|c|c|c|}
\hline \multicolumn{3}{|c|}{$\begin{array}{l}\text { 14. SUBJECT TERMS } \\
\text { Electric propulsion; Ion propulsion }\end{array}$} \\
\hline $\begin{array}{l}\text { 17. SECURITY CLASSIFICATION } \\
\text { OF REPORT } \\
\text { Unclassified }\end{array}$ & $\begin{array}{l}\text { 18. SECURITY CLASSIFICATION } \\
\text { OF THIS PAGE } \\
\text { Unclassified }\end{array}$ & $\begin{array}{l}\text { 19. SECURITY CLASSIFICATION } \\
\text { OF ABSTRACT } \\
\text { Unclassified }\end{array}$ \\
\hline
\end{tabular}



